\title{
PERSPECTIVAS TEÓRICAS DOS CONFLITOS SOCIOAMBIENTAIS NO CAMPO DO DESENVOLVIMENTO
}

\author{
RODRIGUES, Ana Carolina. Eng. Agrônoma e Mestranda em Extensão Rural, UFV. \\ E-mail: carolrodrigues.ana@gmail.com.
}

MAFRA, Rennan Lanna Martins. Professor e orientador no Programa de Pós-graduação em Extensão

Rural, UFV. Departamento de Economia Rural. Universidade Federal de Viçosa. Av. Peter Henry Rolfs, s/n. Campus Universitário. CEP: 36570.000 - Viçosa-MG, Brasil. E-mail: rennan.mafra @ gmail.com.

\section{Resumo}

O contexto atual, marcado pela inspiração econômica desenvolvimentista no discurso do Estado e pela disputa corporativa empresarial em torno da exploração dos recursos ambientais, impõe a necessidade da discussão acerca da interação sociedade-natureza. A partir dessa constatação, este artigo tem como objetivo discutir as principais perspectivas teóricas em relação à dualidade entre o conflito pelos recursose o argumento desenvolvimentista.

Palavras-chave: Conflito socioambiental; Recursos escassos; Racionalidade desenvolvimentista.

\section{THEORETICAL PERSPECTIVES OF THE SOCIOENVIRONMENTAL CONFLICTS IN THE DEVELOPMENT FIELD}

\begin{abstract}
The current context, marked by developmentalist economic inspiration in the state discourse and by the corporate business dispute surrounding the exploitation of environmental resources, imposes the needfor discussion about the nature-society interactions. Starting from this observation, this article has as aim to discuss the major theoretical perspectives in relation to the duality between the conflict over resources and the developmentalist argument.
\end{abstract}

KEYwORDS: Environmental Conflict; Scarce Resources; Developmentalist Rationality. 


\section{INTRODUÇão}

É certo que, embora estabelecidas sobre bases produtivas distintas, em termos práticos, as estratégias reproduzidas por grandes empresas dos segmentos da mineração, da geração de energia e do agronegócio têm em comum o uso predatório dos recursos ambientais. Entretanto, tal constatação se torna perigosamente mais complexa quando se toma em conta a influência do Estado, que fornece o discurso econômico legitimador para o avanço dos empreendimentos ligados a essas empresas.

As ações dessas corporações, grande parte delas multinacionais geridas por redes complexas ligadas ao mercado financeiro, tem especial importância nos países em desenvolvimento, em razão dos processos de internacionalização do capital e da base produtiva nas economias nacionais dos países desenvolvidos e nos segmentos empresarias (ZUCOLOTO e CASSIOLATO, 2012), convertendo-se em lugares nos quais atuam sob maior possibilidade de conflitos, considerando as assimetrias socioespaciais e econômicas, por vezes, atenuadas por tais atividades (RIBEIRO, 2008). Nesse sentido, procura-se compreender quais abordagens teóricas dos conflitos socioambientais fornecem instrumentos para o seu entendimento dentro de uma lógica orientada pela racionalidade desenvolvimentista. Para tal, buscou-se compreender, num primeiro momento, o surgimento de uma racionalidade desenvolvimentista pautada no crescimento econômico e, no segundo momento, expor uma proposta teórica de abordagem do desenvolvimento a partir dos conceitos defendidos pelos teóricos do conflito.

\section{A racionalidade do deSenvolvimento}

Como e por que "desenvolvimento"? Essa é a pergunta que não se faz em diversos espaços: alguns informais, outros argumentativos e outros decisórios. Todos esforçados na tarefa de promovê-lo, deixaram de imaginar se ele era mesmo necessário. É claro que essa discussão tem um fundo moral a ser respondido, a seu tempo, por cada sociedade, mas também tem um fundo comparativo. Eé precisamente esse aspecto comparativo que passou a nortear as decisões econômicas da modernidade. Não que seja vinculante à modernidade, mas, como se verá adiante, esse fenômeno tem um lugar reservado no tempo e no espaço.

A racionalidade desenvolvimentista não surgiu. Ela foi, retoricamente, desenvolvida a partir de um complexo de elaborações intersubjetivas protagonizado pela sociedade ocidental. Castoriadis (1981) revela que a incrível obra desenvolvimentista tem origem na fé alimentada pelas religiões ocidentais, a partir das quais conceitos de infinito e de eterno concluem um imaginário incompatível com o mundo vivido. É nessa esperança que repousa a gênese da busca incessante pelo crescimento, sem haver, diversas vezes, razões esclarecidas para tal.

Entretanto, não bastou à sociedade ocidental procurar pelo crescimento sozinha. Novamente, Castoriadis (1981) destaca o papel da ciência, que matematizou a natureza sob a forma de leis, "cartesianizou" a forma de o homem compreender o espaço e de se compreender no espaço. O todo é dividido, conhecido e, depois, reunido. Dessa complexidade das leis matemáticas derivou a economia, que passou a contabilizar a produção humana. Da sua junção com o evolucionismo biológico, nasceu a perspectiva de "amadurecimento" que a economia preservou. Inicialmente, concebeu-se esse amadurecimento de forma simples: mediu-se o aumento linear da produção humana e acreditou-se, por algum tempo, que este fosse ilimitado. Foram necessárias algumas crises econômicas e revoltas sociais para que se compreendesse que isso não era verdade.

Às revoltas sociais respondeu-se incorporando predicados ao desenvolvimento: ele começou timidamente a ficar mais "social" e mais "verde" por causa da influência dos movimentos sociais da década de 1960 (CASTORIADIS, 1981); há algum tempo é entendido como sinônimo de "liberdade" (SEN, 2010) e se envolve com conceitos amorfos como sustentabilidade e participação.

Às crises, respondeu-se com mais acumulação, aliás, criou-se também mecanismos eficientes que 
virtualizaram e desterritorializaram a acumulação, como é o caso do mercado financeiro (PAULANI, 2009). Na verdade, o vulto da crise é sempre determinante para essa racionalidade desenvolvimentista: dela procura se afastar, mas nela se fundamenta. Para Harvey (2011), as crises são inevitáveis em um sistema que procura constantemente por mais acumulação dentro de um universo de recursos - o planeta Terra - finito.

Portanto, por mais que procure se distanciar dessa crítica elementar à racionalidade desenvolvimentista, pareceria ingênuo acreditar que ela, por sua vez, se afastou do objetivo de crescimento econômico pelo fato de ter acolhido novos significados. Portanto, o que restou foi o seminal crescimento econômico. E ele é usado a todo tempo para justificar a pilhagem legitimada pelos governos no mundo inteiro sobre os recursos ambientais, até porque fica cada vez mais evidente que há, inclusive, uma espécie de competição pela confiança dos investidores entre quem cresce aumenta seu Produto Interno Bruto (PIB) - e quem não cresce. Há exemplos em todo o mundo em termos da pressão, por vezes intragovernamental, pela flexibilização das condições - especialmente em termos das legislações ambientais, trabalhistas e fiscais - para a instalação de grandes empresas que gerarão crescimento econômico. Situações como essa se encontram ilustradas em eventos recentes: a corrida energética brasileira, o Código Florestal e até mesmo as explorações de carvão em Moçambique (MOSCA \& SELEMANE, 2011; UNAC, 2011; CASTELBRANCO, 2010; VUNJANHE, 2011).

Mesmo considerando todas essas questões aparentemente determinadas, não deixou de haver uma contracorrente questionando o desenvolvimento - não tanto do ponto de vista da sua necessidade, mas sim dos seus meios -, especialmente os movimentos sociais e ambientais, os quais alimentam uma pauta extensa de injustiças e de demandas não atendidas, reafirmando, para todos os efeitos, o protagonismo da sociedade civil na definição dos usos e do poder sobre os recursos ambientais.

Além disso, cada vez mais teóricos do desenvolvimento o têm visto como um campo, na perspectiva de Bourdieu, e um campo de poder. Ribeiro (2008) partilha desse olhar argumentando, entre outras questões, que se trata de um campo em que o poder é determinado pelo controle de recursos. Para Viégas (2009) esse controle está para além dos recursos, é uma disputa pelo controle do território. Ambos concordam que essa disputa, muitas vezes, se estabelece em termos simbólicos e abarca as mais variadas dimensões da experiência humana entre os atores envolvidos na disputa.

\section{AS DIMENSÕES CONCEITUAIS DO CONFLITO AMBIENTAL: ELABORAÇÕES A PARTIR DA RACIONALIDAdE DESENVOLVIMENTISTA}

Anterior à discussão do conflito ambiental, há que se explorar com mais propriedade as perspectivas de conflito. Trata-se de um entendimento inicial que tem por razão contribuir para a desmistificação de uma sociedade pacífica baseada num tecido social que não se perturba e não se rompe, e de que, quando se rompe, esse movimento deve ser, sutilmente, posto a termo.

O conflito é assumido aqui como parte da trajetória de sociabilidade humana, desde a complexa normatização medieval em torno do conceito de civilité, descrita por Elias (1994), até se tornar, ele mesmo, elemento estruturador da própria sociabilidade, remetendo-se à perspectiva de Simmel (1983), sob a qual se entende a dialética entre o conflito e o nãoconflito como elemento de formação e/ou rompimento do corpo social. Para Simmel (1983), o poder enriquecedor do conflito está no fato de que ele, ao invés de dividir o corpo social, o transforma positivamente em um espaço onde as posições dos sujeitos são reconhecidas:

(...) um "conflito" (...), não só pelo fato de que a opressão costuma aumentar quando é suportada calmamente e sem protestos, mas também porque a oposição nos dá satisfação íntima, distração, alívio, assim como, sob condições psicológicas diferentes, nos dá humildade e paciência." (SIMMEL, 1983, p. 127). 
Não convém abordar a longa trajetória dos estudos sobre conflito e suas raízes na divisão da sociedade seja em classes, como Marx defendeu, ou com base nos interesses individuais, como supuseram os liberais , em virtude do escopo reduzido que abrange este artigo. Entretanto, é preciso clarificar que a perspectiva de conflito, tomada como característica da sociabilidade humana, se distancia de uma "solução" consensual:

Discutir o conceito de conflito, processo que ocupa lugar essencial nas mais diversas teorias sociológicas, clássicas e contemporâneas, implica também discutir as oposições paradigmáticas aí presentes como integração e ruptura, consenso e dissenso, estabilidade e mudança, noções que correspondem a concepções diferentes de sociedade e de produção do conhecimento (VIÉGAS, 2009, p.146).

No contexto do desenvolvimento, a eminência do conflito, especialmente aquele relacionado ao espaço e aos seus recursos, está ligada aos pressupostos de territorialização humana, entendendo esta como ação que visa estabelecer controle sobre um determinando território.

(...) a ecologia humana se caracteriza pelo conflito social, no sentido que os humanos não possuem instruções biológicas sobre o emprego exossomático da energia e dos materiais, sendo nossa territorialidade construída politicamente (MARTINEZ, 2011, p. 110).

De acordo com Acselrad (2009), a oposição elementar ocorre entre modelos de desenvolvimento e racionalidades não hegemônicas. Ele argumenta que os usos e apropriações do espaço não podem se resumir à esfera do mercado, pois estão também ligados ao "exercício de racionalidades não hegemônicas". É nesse contexto que "os conflitos ambientais podem ser entendidos como expressão de tensões no processo de reprodução dos modelos de desenvolvimento" (ACSELRAD, 2009, p. 18).
Para Acselrad (2009), "eficiência" e "competitividade", preconizadas pela racionalidade desenvolvimentista, são critérios hegemônicos acerca dos quais cabe contestação apenas mediante "uma inflexão nos esquemas de percepção que legitimam a distribuição de poder sobre os recursos do território" (ACSELRAD, 2009, p. 24). Tal inflexão engloba a luta pelo poder na apropriação do território e pelo reconhecimento de categorias e práticas sociais.

Viégas (2009), ao descrever o campo ambiental, destaca a sua dimensão conflitiva, que está amparada pela pluralidade e pela complexidade da sociedade moderna, sob a qual convivem formas tradicionais e modernas de experimentar o mundo:

O campo ambiental, tal como os campos jurídico e político definidos por Bourdieu, constitui-se também em um espaço social de diferenciações, onde são travadas lutas de poder e lutas simbólicas, no bojo das quais agentes se esforçam para manter ou para transformar a estrutura das relações existentes no campo, legitimando ou deslegitimando práticas sociais ou culturais. No interior deste espaço de posições ligadas por relações de força específicas, os indivíduos estão dispostos de acordo com estruturas desiguais de acesso, uso, apropriação, distribuição e controle sobre os territórios e sobre o conjunto de recursos materiais e simbólicos.(...) São estas lógicas culturais em disputa que instituem os conflitos no campo ambiental: lutas em torno de formas diferenciadas de apropriação e uso materiais territorializados, ancorados em significados também diversos atribuídos a estes mesmos recursos (VIÉGAS, 2009, p.153).

Portanto, nisso se firma o pressuposto do poder dentro do campo: o controle de um território, o qual se estabelece baseado em uma racionalidade. A oposição entre a racionalidade desenvolvimentista e a racionalidade ambiental cria um abismo entre as percepções e usos estabelecidos pelos diferentes agentes, o que, inúmeras vezes, tornam evidentes os 
desequilíbrios de poder na sociedade capitalista. $\mathrm{O}$ conflito que se estabelece, então, tem por premissa colocar em xeque o argumento hegemônico e expansionista do crescimento que orienta a racionalidade desenvolvimentista.

Portanto, a construção de uma racionalidade ambiental implica na necessidade de desconstruir os conceitos de diversas ciências e campos disciplinares do saber, assim como os sistemas de valores e as crenças em que se funda e que promovem a racionalidade econômica e instrumental na qual repousa uma ordem social e produtiva insustentável (MUNIZ, 2009, p. 184).

Por isso, Acselrad (2009) argumenta que há, no contexto desenvolvimentista atual, sustentado pela perspectiva de exploração dos recursos naturais como forma de acumular riquezas, uma necessidade de novos elementos analíticos para compreender a relação entre conflitos sociais e ambientais, de forma a entender "a natureza no interior do campo dos conflitos sociais" (ACSELRAD, 2009, p. 9).

Isso remete à seguinte situação: além de apontar o que se opõe na arena do conflito ambiental, tornase imperioso compreender a dimensão humana desses conflitos que se estabelecem em torno dos recursos ambientais e, posteriormente, os conceitos fundamentais para a sua análise. Para Muniz (2009), os "conflitos distributivos" devem ser expostos a partir dos componentes social e ambiental, tornando-se assim um "conflito socioambiental", uma vez que ele opõe, em última análise, pessoas:

(...) conflitos entre grupos sociais no embate pelo uso dos recursos naturais, os chamados conflitos distributivos, ou simplesmente conflitos socioambientais (MUNIZ, 2009, p. 183).

Essa perspectiva, pautada na oposição entre grupos sociais, se torna salutar quando se toma como referência o lugar dos mais pobres nos contextos de crescimento econômico. É especialmente nas dinâmicas desenvolvimentistas que se dá a apropriação catastroficamente desigual dos recursos ambientais:

As dinâmicas do crescimento econômico geram um processo de exclusão territorial e social, levando à periferização de grande massa de trabalhadores nas cidades; e no campo impulsiona ao êxodo rural para os grandes centros urbanos (MUNIZ, 2009, p. 186-187).

Assim, na esteira das abordagens que localizam os problemas sociais no campo do conflito, Martinez (2011) resume, no "ecologismo dos pobres", os dilemas que envolvem o desenvolvimento nos países em desenvolvimento, e os desequilíbrios de poder a ele associados, os quais são tensionados de ambas as partes: de um lado pelo discurso associado à racionalidade desenvolvimentista orientada pelo crescimento econômico e, de outro, as articulações de movimentos sociais e atores políticos reivindicantes dos direitos dos "atingidos" ou simplesmente marginalizados pelo processo, muito embora não deixem de sofrer com as suas consequências nefastas:

Quais os valores colocados em jogo pelos ativistas protetores dos rios nas suas lutas locais contra as grandes represas? Em alguns momentos, no Norte, eles defendem o valor das atrações naturais, ou a "ecologia profunda", que dão um caráter sagrado à natureza. Ao mesmo tempo, no Sul a sobrevivência material é frequentemente o valor fundamental, compatível com o sagrado, com o estético e com o respeito devotado a todas as formas de vida. No Norte, a oposição às represas decorre muitas vezes de grupo de pessoas preocupadas com a desapropriação de belezas naturais ou pela perda de prazeres como descer navegando rio abaixo suas corredeiras. No Sul, o antagonismo tem origem, como no movimento dos atingidos por barragens do Brasil, numa população provida de poucas posses em perigo de perder sua fonte de sobrevivência (MARTINEZ, 2011, p. 178). 
Não convém abordar a longa trajetória dos estudos sobre conflito e suas raízes na divisão da sociedade seja em classes, como Marx defendeu, ou com base nos interesses individuais, como supuseram os liberais,em virtude do escopo reduzido que abrange este artigo. Entretanto, é preciso clarificar que a perspectiva de conflito, tomada como característica da sociabilidade humana, se distancia de uma "solução" consensual:

Discutir o conceito de conflito, processo que ocupa lugar essencial nas mais diversas teorias sociológicas, clássicas e contemporâneas, implica também discutir as oposições paradigmáticas aí presentes como integração e ruptura, consenso e dissenso, estabilidade e mudança, noções que correspondem a concepções diferentes de sociedade e de produção do conhecimento (VIÉGAS, 2009, p.146).

No contexto do desenvolvimento, a eminência do conflito, especialmente aquele relacionado ao espaço e aos seus recursos, está ligada aos pressupostos de territorialização humana, entendendo esta como ação que visa estabelecer controle sobre um determinando território.

(...) a ecologia humana se caracteriza pelo conflito social, no sentido que os humanos não possuem instruções biológicas sobre o emprego exossomático da energia e dos materiais, sendo nossa territorialidade construída politicamente (MARTINEZ, 2011, p. 110).

De acordo com Acselrad (2009), a oposição elementar ocorre entre modelos de desenvolvimento e racionalidades não hegemônicas. Ele argumenta que os usos e apropriações do espaço não podem se resumir à esfera do mercado, pois estão também ligados ao "exercício de racionalidades não hegemônicas". É nesse contexto que "os conflitos ambientais podem ser entendidos como expressão de tensões no processo de reprodução dos modelos de desenvolvimento" (ACSELRAD, 2009, p. 18).
Para Acselrad (2009), "eficiência" e "competitividade", preconizadas pela racionalidade desenvolvimentista, são critérios hegemônicos acerca dos quais cabe contestação apenas mediante "uma inflexão nos esquemas de percepção que legitimam a distribuição de poder sobre os recursos do território" (ACSELRAD, 2009, p. 24). Tal inflexão engloba a luta pelo poder na apropriação do território e pelo reconhecimento de categorias e práticas sociais.

Viégas (2009), ao descrever o campo ambiental, destaca a sua dimensão conflitiva, que está amparada pela pluralidade e pela complexidade da sociedade moderna, sob a qual convivem formas tradicionais e modernas de experimentar o mundo:

O campo ambiental, tal como os campos jurídico e político definidos por Bourdieu, constitui-se também em um espaço social de diferenciações, onde são travadas lutas de poder e lutas simbólicas, no bojo das quais agentes se esforçam para manter ou para transformar a estrutura das relações existentes no campo, legitimando ou deslegitimando práticas sociais ou culturais. No interior deste espaço de posições ligadas por relações de força específicas, os indivíduos estão dispostos de acordo com estruturas desiguais de acesso, uso, apropriação, distribuição e controle sobre os territórios e sobre o conjunto de recursos materiais e simbólicos.(...) São estas lógicas culturais em disputa que instituem os conflitos no campo ambiental: lutas em torno de formas diferenciadas de apropriação e uso materiais territorializados, ancorados em significados também diversos atribuídos a estes mesmos recursos (VIÉGAS, 2009, p.153).

Portanto, nisso se firma o pressuposto do poder dentro do campo: o controle de um território, o qual se estabelece baseado em uma racionalidade. A oposição entre a racionalidade desenvolvimentista e a racionalidade ambiental cria um abismo entre as percepções e usos estabelecidos pelos diferentes agentes, o que, inúmeras vezes, tornam evidentes os 
desequilíbrios de poder na sociedade capitalista. $\mathrm{O}$ conflito que se estabelece, então, tem por premissa colocar em xeque o argumento hegemônico e expansionista do crescimento que orienta a racionalidade desenvolvimentista.

Portanto, a construção de uma racionalidade ambiental implica na necessidade de desconstruir os conceitos de diversas ciências e campos disciplinares do saber, assim como os sistemas de valores e as crenças em que se funda e que promovem a racionalidade econômica e instrumental na qual repousa uma ordem social e produtiva insustentável (MUNIZ, 2009, p. 184).

Por isso, Acselrad (2009) argumenta que há, no contexto desenvolvimentista atual, sustentado pela perspectiva de exploração dos recursos naturais como forma de acumular riquezas, uma necessidade de novos elementos analíticos para compreender a relação entre conflitos sociais e ambientais, de forma a entender "a natureza no interior do campo dos conflitos sociais" (ACSELRAD, 2009, p. 9).

Isso remete à seguinte situação: além de apontar $o$ que se opõe na arena do conflito ambiental, tornase imperioso compreender a dimensão humana desses conflitos que se estabelecem em torno dos recursos ambientais e, posteriormente, os conceitos fundamentais para a sua análise. Para Muniz (2009), os "conflitos distributivos" devem ser expostos a partir dos componentes social e ambiental, tornando-se assim um "conflito socioambiental", uma vez que ele opõe, em última análise, pessoas:

(...) conflitos entre grupos sociais no embate pelo uso dos recursos naturais, os chamados conflitos distributivos, ou simplesmente conflitos socioambientais (MUNIZ, 2009, p. 183).

Essa perspectiva, pautada na oposição entre grupos sociais, se torna salutar quando se toma como referência o lugar dos mais pobres nos contextos de crescimento econômico. É especialmente nas dinâmicas desenvolvimentistas que se dá a apropriação catastroficamente desigual dos recursos ambientais:

As dinâmicas do crescimento econômico geram um processo de exclusão territorial e social, levando à periferização de grande massa de trabalhadores nas cidades; e no campo impulsiona ao êxodo rural para os grandes centros urbanos (MUNIZ, 2009, p. 186-187).

Assim, na esteira das abordagens que localizam os problemas sociais no campo do conflito, Martinez (2011) resume, no "ecologismo dos pobres", os dilemas que envolvem o desenvolvimento nos países em desenvolvimento, e os desequilíbrios de poder a ele associados, os quais são tensionados de ambas as partes: de um lado pelo discurso associado à racionalidade desenvolvimentista orientada pelo crescimento econômico e, de outro, as articulações de movimentos sociais e atores políticos reivindicantes dos direitos dos "atingidos" ou simplesmente marginalizados pelo processo, muito embora não deixem de sofrer com as suas consequências nefastas:

Quais os valores colocados em jogo pelos ativistas protetores dos rios nas suas lutas locais contra as grandes represas? Em alguns momentos, no Norte, eles defendem o valor das atrações naturais, ou a "ecologia profunda", que dão um caráter sagrado à natureza. Ao mesmo tempo, no Sul a sobrevivência material é frequentemente o valor fundamental, compatível com o sagrado, com o estético e com o respeito devotado a todas as formas de vida. No Norte, a oposição às represas decorre muitas vezes de grupo de pessoas preocupadas com a desapropriação de belezas naturais ou pela perda de prazeres como descer navegando rio abaixo suas corredeiras. No Sul, o antagonismo tem origem, como no movimento dos atingidos por barragens do Brasil, numa população provida de poucas posses em perigo de perder sua fonte de sobrevivência (MARTINEZ, 2011, p. 178). 
Muito embora diversas situações que evidenciam a dimensão social do conflito ambiental estejam muito bem desenhadas na sociedade contemporânea, existem outros tratamentos dados ao tema que requerem atenção aqui, especialmente por se oporem à politização da disputa ambiental, compondo, na maioria das vezes, os discursos institucionais conciliadores dos órgãos governamentais e dos departamentos de relações públicas das grandes empresas. Assim, essa perspectiva de consenso remete particularmente às situações que emanam dos projetos de desenvolvimento, os quais buscam estabelecer formas de "compensação" pelas perdas materiais e imateriais decorrentes da instalação e do funcionamento de um empreendimento.

Para Acselrad (2009), a intenção em torno do consenso é representada pelo esforço empreendido no sentido de silenciar um conjunto de debates que vêm sendo travados, especialmente a partir dos anos 1990, acerca do próprio modelo de desenvolvimento pautado pela exploração predatória dos recursos naturais e, da mesma forma, dar voz aos agentes impactados por empreendimentos com vistas ao desenvolvimento, trazendo à tona suas respectivas racionalidades e experiências sociais - comunidades indígenas, ribeirinhas, rurais, entre outras:

(...) merece particular atenção o esforço crescentemente generalizado de criação, em inúmeros países da América Latina, de projetos voltados para a disseminação de tecnologias de resolução de conflitos ambientais. Em muitos casos, originários em instituições sediadas em países centrais, voltadas para a "capacitação" de entidades e comunidades de países periféricos, tais iniciativas pretendem a difusão de modelos de análise e ação que pressupõem que a "falta de instituições" está na origem dos conflitos ambientais, e que a paz e a harmonia deveria provir de um processo de despolitização dos conflitos através de táticas de negociação direta capazes de prover "ganhos mútuos". Trata-se de psicologizar o dissenso, prevenindo conflitos e tecnificando seu tratamento através de regras e manuais destinados a transformar os "pontos quentes" em "comunidades de aprendizado" (ACSELRAD, 2009, p. 10).

No centro da negação do conflito está a confluência conceitual para a tentativa de conciliação entre desenvolvimento e preservação ambiental, que se expressa na teoria da "modernização ecológica". Tal discurso se ancora no intuito modernizador lastreado em perspectivas conservadoras, a partir das quais se constrói a imediata correlação entre riqueza/ desenvolvimento e preservação ambiental:

O termo "modernização ecológica" ficou conhecido por designar uma série de estratégias de cunho neoliberal para o enfrentamento do impasse ecológico sem considerar sua articulação com a questão da desigualdade social. A estratégia da modernização ecológica é aquela que propõe conciliar o crescimento com a resolução dos problemas ambientais, dando ênfase à adaptação tecnológica, à celebração da economia de mercado, à crença na colaboração e no consenso. Além de legitimar o livre-mercado como melhor instrumento para equacionar os problemas ambientais, esta concepção procurou fazer do meio ambiente uma razão a mais para se implementar o programa de reformas liberais (ACSELRAD, 2009, p. 14).

Partindo dessa perspectiva de modernização ecológica, Veyret (2007a) elenca uma série de riscos - tendo como principais o industrial, o agrícola, o nuclear e o natural - e demonstra, pelo menos a partir da realidade dos países desenvolvidos, a eficiência que o monitoramento e a gestão de cada um destes no sentido de garantir a "segurança" de grandes contingentes populacionais e do meio ambiente que circundam tais instalações. Naturalmente, uma política tecnológica dos órgãos reguladores, associada a medidas de poder coercitivo do Estado, são determinantes para a segurança das pessoas; porém, 
está aí presente um discurso tecnocrático que visa, ao mesmo tempo, homogeneizar a perspectiva do risco e despolitizar - tecnocratizando - a discussão sobre gestão desses riscos. Essa perspectiva da autora, que também remonta o discurso da racionalização no uso dos recursos ambientais por meio de constantes incrementos tecnológicos, está presente no discurso modernizador sobre o qual os atores econômicos, baseados na racionalidade desenvolvimentista, procuram justificar o crescimento econômico como instrumento de rompimento com a pobreza nos países em desenvolvimento, como no exemplo dos países africanos fornecido por ela mesma:

(...) deve ser integrada a uma perspectiva de desenvolvimento maior, que favoreça a infraestrutura, a urbanização e o crescimento industrial, única maneira de absorver efetivos populacionais que se tornariam, então excedentes em relação às necessidades de uma agricultura moderna (VEYRET, 2007b, p. 131).

Martinez (2011) procura desconstruir essa perspectiva da racionalidade desenvolvimentista apoiada na tríade modernização-industrialização-urbanização, com base na compreensão ecológica de tais processos, isto é, fundamentalmente em termos de desbalanço energético que a urbanização, combinada coma industrialização maciça, produzem, se comparadas às formas tradicionais de vida camponesas:

Manter o campesinato mundial não economizaria em si muita energia, se compararmos com a energia consumida pelas grandes economias modernas. Por outro lado, os efeitos colaterais da industrialização e da urbanização ao estilo ocidental na China, Índia, Indonésia e África seriam extremamente significativos (MARTINEZ, 2011, p. 111).

A ideia de compensação econômica também encontra legitimidade dentro do discurso do consenso, por sua vez, promovido pela modernização ecológica, na medida em que o "argumento" econômico é considerado preponderante dentro das esferas públicas de decisão. Nesse sentido, o mesmo discurso - econômico - que tensiona a arena democrática a seu favor, também desconsidera as dimensões imateriais presentes na argumentação das comunidades atingidas, buscando formas consensuais de ressarcimento baseado em uma única acepção do que vem a ser "valor":

A resolução de conflitos e a política pública frequentemente solicitam uma redução ou simplificação forcada da complexidade, negando, portanto, legitimidade de alguns pontos de vista. Às vezes os conflitos ecológicos distributivos podem se mostrar como discrepâncias na valoração no interior de um único padrão de valor, como quando se pede uma compensação monetária por externalidades (MARTINEZ, 2011, p. 211).

Portanto, considera-se que, pelas razões mencionadas, a modernização ecológica está na posição diametralmente oposta ao que se pretende entender como conflito socioambiental. Por entender o conflito como intrínseco à interação entre as diferenças em sociedade, o esforço teórico para entender as disputas por recursos deve considerar o conflito não como uma fissura social, a ser encoberta ou como um tecido rasgado que precisa ser imediatamente costurado, ou ainda como um jogo em que se ganha independentemente do time em que se joga.

Nesse sentido, no campo acadêmico, tanto a abordagem da "justiça ambiental" quanto a da "ecologia política" se complementam, trazendo à tona a possibilidade de se estudar as disputas pelos recursos ambientais a partir do seu conflito imanente. Assim, a definição desses dos dois termos visa evidenciar as partes envolvidas e suas respectivas posições de poder, entendendo o conflito socioambiental como uma totalidade, um fato social completo ligado à relação homem-natureza, ao contrário de tentar determinar bases para a sua solução, já pressupondo que o princípio de solução é o fim do conflito. 
A ecologia política amplia a crítica dos fundamentos filosóficos da economia neoclássica através de questões como os conflitos distributivos e a incomensurabilidade dos valores ambientais, ao avançar para além da economia política de tradição marxista, incorporando questões ecológicas no entendimento das dinâmicas econômicas e de poder que caracterizam as sociedades modernas (MUNIZ, 2009, p. 185).

Para propor uma abordagem fundamentada na ecologia política e na justiça ambiental, é essencial apresentar dois conceitos:

(...) a Ecologia Política aborda o conceito de conflitos socioambientais, como sendo os conflitos que surgem a partir da disputa pelo acesso aos bens e serviços ambientais, ou seja, são conflitos que travados em torno dos problemas do uso e da apropriação dos recursos naturais; confronto entre atores sociais que defendem diferentes lógicas para a gestão dos bens coletivos de uso comum (MUNIZ, 2009, p. 181).

Para designar esse fenômeno de imposição desproporcional dos riscos ambientais às populações menos dotadas de recursos financeiros, políticos e informacionais, tem sido consagrado o termo injustiça ambiental. Como contraponto, cunhou-se a noção de justiça ambiental para denominar um quadro de vida futuro no qual essa dimensão ambiental da injustiça social venha a ser superada. Essa noção tem sido utilizada, sobretudo, para construir uma nova perspectiva a integrar as lutas ambientais e sociais (ACSELRAD, 2009, p. 9).

Dessa forma, é possível retomar a racionalidade desenvolvimentista, tendo-a como pano de fundo para se lançar a ecologia política como base epistêmica para o entendimento da justiça ambiental. Trata-se de compreender o papel das disputas dentro do campo do desenvolvimento no sentido estruturador, formador de opinião e transformador do papel dos sujeitos, numa sociedade que começa a atentar para a indissociabilidade entre manutenção da vida e usos dos recursos ambientais:

Nos últimos anos o campo de discussão da ecologia política tem sido revigorado pela discussão sobre a justiça ambiental, para a qual serve como base teórica ao analisar os conflitos distributivos a partir das desigualdades decorrentes de processos econômicos e sociais, que acabam por concentrar as principais cargas de poluição e demais efeito deletérios do desenvolvimento sobre as populações mais pobres, discriminadas e socialmente excluídas (MUNIZ, 2009, p. 186-187).

Sendo assim, não é possível compreender a noção de justiça ambiental apartada de uma discussão sobre a racionalidade desenvolvimentista e sobre o lugar do conflito socioambiental como produtor de resistência, diante de um crescimento econômico que se pretende avassalador. Tal conflito reverbera para além dos diretamente afetados: ele toca as franjas simbólicas do sistema e provoca rachaduras na linearidade do tempo, ao revelar a condição desigual e desumana existente, paradoxalmente, a partir e em nome de um processo supostamente inquestionável de desenvolvimento. Em outras palavras: o conflito parece ser a única instância organizadora, capaz de engendrar uma complexa discussão sobre justiça, equidade e vida, com vistas a não somente enfrentar, mas a demonstrar (cientificamente, como bem gosta e exige a modernidade) o desenvolvimento e seus dramas sociais (RIBEIRO, 2008).

\section{Considerações Finais}

A partir das perspectivas elencadas aqui para o olhar sobre o conflito socioambiental, podem-se encontrar justificativas para o estabelecimento do que seria "um novo paradigma de desenvolvimento". Muniz (2009), citando Santilli (2005) ${ }^{1}$, esboça uma hipótese 
conceitual para esse novo paradigma, que chamou de "sociambientalismo":

(...) [um] novo paradigma de desenvolvimento deve promover não somente a sustentabilidade estritamente ambiental, como também a sustentabilidade social. Parte do pressuposto de que as políticas públicas ambientais somente têm eficácia social e sustentabilidade política quando incluem comunidades locais e promovem uma repartição socialmente justa e eqüitativa dos benefícios derivados da exploração dos recursos naturais (MUNIZ, 2009, p. 193) [grifos nossos].

Sendo assim, não é possível dar por encerrada a discussão conceitual sobre conflitos socioambientais. Tampouco se esgota a perspectiva de um novo paradigma para o desenvolvimento. Porém, há que se tomar emconta que remediar o desenvolvimento, sem reelaborar a racionalidade sob o qual ele está fundamentado, é semelhante à tarefa de "enxugar o gelo". Nisso possivelmente se erijam as bases para uma nova compreensão de como devemos continuar crescendo, porém não se terá atingido - ainda que haja esse desejo - o cerne dessa questão, que consiste em encontrar um novo paradigma para a racionalidade.

De tal sorte, pensar o conflito socioambiental enquanto possibilidade saliente para a exposição dos dramas desenvolvimentistas é gesto, sobretudo, político. Aponta Jacques Rancière (2005) que as cenas de dissenso, engendradas esteticamente por sujeitos que se sentem afetados no espaço público, são movimentos fundamentais à produção do novo. $\mathrm{O}$ conflito socioambiental revela-se enquanto lugar produtor dessas cenas: são sofrimentos de sujeitos concretos, que perdem suas casas, suas histórias, e precisam construir novas narrativas, lançando mão, sobretudo, de estratégias voltadas a uma espécie de partilha do sensível. Ainda que uma dimensão estética da experiência seja rejeitada, enquanto premissa, pela racionalidade desenvolvimentista, sua suposta fraqueza inofensiva pode ser capaz de conformar o lugar do inédito, como aponta o entusiasmo de Muniz (2009) acerca da emergência de um novo paradigma.

Parece ser ainda cedo para uma aceitabilidade irrefutável sobre tal emergência, ainda que as cenas de dissenso e a presença do conflito no espaço público já insinuem, há muito tempo, o colapso desenvolvimentista. Por isso, o conflito carrega o indigesto indício de dor e sofrimento, e produz visibilidade da falência do desenvolvimento - gesto necessário que expõe o furor totalizante do crescimento e, a ele, produz resistência. O que se espera é a mudança, esta que não depende unicamente do conflito, mas de uma alteração de poder: uma falência do centro, um esgotamento paradigmático, uma crise de proporções ainda desconhecidas.

\section{REFERÊNCIAS}

ACSELRAD, Henri. As Práticas Espaciais e o Campo dos Conflitos Ambientais. In. ACSERALD, Henri (Org.). Conflitos Ambientais no Brasil. Rio de Janeiro: Relume-Dumará: Fundação Heinrich Böll, 2004, p. 13-35.

ACSELRAD, Henri; MELLO, Cecília Campello do A.; BEZERRA, Gustavo das Neves. O que é justiça ambiental. Rio de Janeiro: Garamond, 2009. 160 p.

CASTEL-BRANCO, Carlos Nuno. Economia extractiva e desafios de industrialização em Moçambique. In: BRITO Luís de; CASTELBRANCO, Carlos N.; CHICHAVA, Sérgio; FRANCISCO, António (Orgs.). Economia extractiva e desafios de industrialização em Moçambique. Maputo, IESE - Instituto de Estudos

\footnotetext{
${ }^{1}$ Apud SANTILLI, Juliana. Sociambientalismo e novos direitos: proteção jurídica àdiversidade biológica e cultural. São Paulo;Petrópolis: IEB/ISA, 2005.
} 
Socio-Econômicos, 2010, p. 19-110.

CASTORIADIS, Cornelius. Reflexões sobre o desenvolvimento e a racionalidade. In:

Revolução e autonomia: umperfil de Cornelius

Castoriadis. Belo Horizonte: Copec, 1981, p. 117-147.

ELIAS, Norbert. A civilização como transformação do comportamento humano. In: . 0 processo civilizador: uma história dos costumes. Rio de Janeiro: Jorge Zahar Editora, 1994, v. I. 277 p.

HARVEY, David. O enigma do capital e as crises do capitalismo. Tradução de João Alexandre Peschanski. São Paulo: Boitempo, 2011. 224p.

MARTINEZ, Allier Joan. O Ecologismo dos pobres: conflitos ambientais e linguagens de valoração. São Paulo: Contexto, 2011. 384 p.

\section{MOSCA, João; SELEMANE, Tomás. El dorado} de Tete: os megaprojectos de mineração. Maputo, CIP - Centro de Integridade Pública, 2011. 74 p. MUNIZ, Lenir Moraes. Ecologia Política: o campo de estudo dos conflitos socioambientais. Revista Pós-Ciências Sociais, UFMA, v. 6, n. 12, p. 181196, 2009.

PAULANI, Leda M. A crise do regime da acumulação com dominância da valorização financeira e a situação do Brasil. Revista Estudos Avançados, v. 23, n. 66, p. 25-39, jun/2009.

RANCIÈRE, Jacques. A partilha do sensível: estética e política. Trad. Mônica Costa Netto. São Paulo: Eixo/Editora 34, 2005.69 p.

RIBEIRO, Gustavo L. Poder, Redes e Ideologia no campo do Desenvolvimento. Revista Novos

Estudos, CEBRAP, vol. 80, p. 109-125, mar/2008.
SEN, Amartya. Desenvolvimento como liberdade. Tradução Laura Teixeira Motta. São Paulo: Companhia das Letras, 2010. 416 p.

SIMMEL, Georg. Sociologia. In: MORALES FILHO, Evaristo (Org). Simmel. São Paulo: Editora Ática, 1983.

UNAC e Justiça Ambiental. Os Senhores da TerraAnálise Preliminar do Fenómeno de Usurpação de Terra em Moçambique. Maputo, Março de 2011.74 p.

VEYRET, Yvette. Os tipos de risco. In:

Os riscos: o homem como agressor e vítima do meio ambiente. São Paulo: Contexto, 2007a, p 63-80.

VEYRET, Yvette. O risco alimentar na África. In: Os riscos: o homem como agressor e vítima do meio ambiente. São Paulo: Contexto, 2007b, p. 113-132.

VIÉGAS, Rodrigo Nuñez. Conflitos ambientais e lutas materiais e simbólicas. Revista Desenvolvimento e Meio Ambiente, Editora UFPR, n. 19, p. 145-157, jan/jun, 2009.

VUNJANHE, Jeremias. Impactos sociais da exploração de minerais em Moçambique: o caso da Vale. In: SEMINÁRIO DAPLATAFORMADA SOCIEDADE CIVIL SOBRE PETRÓLEO, GÁS E MINERAIS. 24 de fev de 2011, Maputo. Disponível em <http://www.iese.ac.mz/ ?blogviewid=210\&_target__= acesso em: $11 \mathrm{dez}$. 2013.

ZOCOLOTO, Graziela Ferrero; CASSIOLATO, José Eduardo. Desenvolvimento tecnológico por origem de capital: a experiência brasileira recente. Revista Brasileira de Inovação, Campinas, v. 12, n 1, p.133-170, jan/jun 2013.

RECEBIDO EM 15/7/2013

Aсегто Eм 16/12/2013 